\title{
A MULTICENTRE STUDY ON AVERAGE WARFARIN DOSE TO MAINTAIN THERAPEUTIC INTERNATIONAL NORMALISED RATIO WITH TIME IN THERAPEUTIC RANGE OF MORE THAN 75\% IN ATRIAL FIBRILLATION PATIENTS
}

\author{
ANG KEE HOOI", ISHMAH MUSFIRAH NAZARI, LOW SEOW HUEY, NG YINWEN, \\ OON XIN YING AND VALLIYAMAI A/P SUPPIAH \\ Pharmacy Department, Hospital Pulau Pinang, Georgetown, Pulau Pinang, Malaysia
}

Published online: 23 November 2021

To cite this article: ANG KEE HOOI, ISHMAH MUSFIRAH NAZARI, LOW SEOW HUEY, NG YINWEN, OON XIN YING \& VALLIYAMAI A/P SUPPIAH (2021) A multicentre study on average warfarin dose to maintain therapeutic international normalised ratio with time in therapeutic range of more than $75 \%$ in atrial fibrillation patients, Malaysian Journal of Pharmaceutical Sciences. 19(2): 47-60. https://doi.org/10.21315/mjps2021.19.2.3

To link to this article: https://doi.org/10.21315/mjps2021.19.2.3

\begin{abstract}
Large interindividual variability and over-anticoagulation resulting bleeding complications due to narrow therapeutic index of warfarin has causes its pharmacodynamic activity to be highly variable. Studies shown that ethnicity, age and gender contribute to warfarin response variability. Good coagulation control of time in therapeutic range (TTR) $>75 \%$ was chosen to determine the average warfarin dose in atrial fibrillation (AF) among ethnicity, age and gender. Data from Warfarin Medication Therapy Adherence Clinic of selected Pulau Pinang hospitals were used for the analysis of average warfarin dose in AF among ethnicity, age and gender. Patients who fulfilled the inclusion criteria from 2015-2016 were followed up for a year. Five hundred and seventy-six patients were included. Two hundred and ten patients had good coagulation control of TTR $>75 \%$ with mean warfarin dose of $3.05 \pm 1.25 \mathrm{mg}$. Only Chinese and Indian have significant difference in average warfarin dose with $2.86 \pm$ $1.10 \mathrm{mg}$ and $4.11 \pm 1.40 \mathrm{mg}$, respectively $(p=0.008)$. Average warfarin dose was found not significantly different among gender and age. As for TTR achievement, 210 (36.4\%) were able to achieve TTR > 75\%, 134 patients achieved TTR 60\%-75\% and 232 patients has TTR $<60 \%$. The median day to achieve three consecutive targeted international normalised ratio (INR) is 186.5 days for atrial fibrillation patient newly started on warfarin therapy in 2015 until 2016. Indian patients required a higher warfarin dose than Chinese patients. This study found that mean warfarin doses were not affected by age and sex.
\end{abstract}

"Corresponding author: kee_hooi_88@hotmail.com

(c) Penerbit Universiti Sains Malaysia, 2021. This work is licensed under the terms of the Creative Commons Attribution (CC BY) (http://creativecommons.org/licenses/by/4.0/). 
Keywords: Warfarin, Atrial Fibrillation, Time in Therapeutic Range, International normalised ratio

\section{INTRODUCTION}

Warfarin is one of the most frequently prescribed oral anticoagulants to reduce thrombosis related risk, morbidity and mortality in patient with atrial fibrillation (AF), mechanical heart valves, deep vein thrombosis (DVT) and pulmonary embolism (PE) (Sonuga et al. 2016). Warfarin has been safe and effective treatment for stroke reduction in AF patients (Brass et al. 1997). However, warfarin initiation therapy has been impeded with two major issues which are large interindividual variability in maintenance dose and over-anticoagulation response, resulted bleeding complications (Ohara et al. 2014). Close monitoring of international normalised ratio (INR) and appropriate dosing are the utmost importance to ensure the warfarin therapeutic efficacy, as its narrow therapeutic index and large interindividual variability may cause its pharmacodynamic activity to be highly variable (Sonuga et al. 2016; Gan et al. 2011).

Malaysia is a multiracial country consisting of three major ethnic groups which are Malay, Chinese and Indian. Several studies have reported that racial differences do influence warfarin maintenance dose as the Asian population requires lower warfarin dose and the Indian patients requires higher warfarin dose to maintain therapeutic INR compared to other races (Gan et al. 2011; Lal et al. 2008; Dang, Hambleton and Kayser 2005). Studies also shown that age and gender have significant contribution in warfarin response variability (Khoury and Sheikh-Taha 2014).

According to Ansell et al. (2004), there is strong relationship between time in therapeutic range (TTR) and events of bleeding or thromboembolism for INR above or below targeted range. Therefore, TTR is often used to represent the coagulation control for warfarin. In ACTIVE W study, association of centre TTR and outcomes were evaluated. The median centre TTR of ACTIVE W study was $65 \%$ and warfarin requires median centre TTR $>65 \%$ to reduce vascular events as compared to combination of clopidogrel and aspirin (Pokorney et al. 2015). The study reported that TTR $<58 \%$ do not generate any clinical benefits (Pokorney et al. 2015). Good INR control was defined by Rosendaal et al. (1993) as TTR $\geq 75 \%$ during study period using the Rosendaal et al.'s method. In White et al. (2007) study, good control group (TTR $>75 \%$ ) has lower rates of annual mortality and major bleeding (1.69\% and $1.58 \%$, respectively) as compared to moderate control group (TTR $65 \%-75 \%$ ) $1.84 \%$ and $1.96 \%$, respectively and poor control group (TTR $<60 \%$ ) $4.20 \%$ and $3.85 \%$, respectively. Furthermore, poor control group reported to have higher rates of myocardial infarction $(1.38 \%$ versus $0.62 \%)$ and stroke or systemic embolic event $(2.10 \%$ versus $1.07 \%$ ) compared to good control group (White et al. 2007).

The objectives of the study were to determine the average warfarin dose in AF patients for TTR more than $75 \%$ among different ethnicity, age group and gender, to determine the TTR of warfarin in Pulau Pinang population, and to determine the median day to achieve a stable therapeutic INR. TTR of more than $75 \%$ is used, to determine the average warfarin dose in AF patients of different ethnicity, age and gender.

Malay J Pharm Sci, Vol. 19, No. 2 (2021): 47-60 


\section{METHODS}

\section{Study Design and Study Population}

This is a retrospective study conducted in four hospitals in Pulau Pinang which was approved by the National Medical Research Register (NMRR) and the Medical Research and Ethics Committee (MREC). All AF patients who are currently under follow up in Warfarin Medication Therapy Adherence Clinic (WMTAC) of Hospital Pulau Pinang, Hospital Seberang Jaya, Hospital Bukit Mertajam and Hospital Kepala Batas during January 2015 until December 2016 were included. This study was conducted over a period of 4 months inclusive of study protocol preparation, study approval application, data collection approval from hospital directors of respective hospitals, data collection, data analysis and dissertation preparation.

All adult patients who are on warfarin for at least a year, with a desired INR range of 2.0-3.0 and have stable INR from 2015-2016 were included. We excluded patients younger than 18 years old, with tuberculosis, pregnant women, patients who defaulted follow up at WMTAC, discontinued warfarin therapy at any point of the study, has interruption in the warfarin therapy for $>7$ days, has a change in INR target within the study period and patients on warfarin for other indications other than AF.

\section{Data Collection}

Case notes of patients were reviewed and data such as age, gender, race, date of clinic appointment, present recommended dose of warfarin and present INR were collected. The patient ethnicity was defined according to national identification documents. During data collection period, we were notified that WMTAC patient under Hospital Seberang Jaya has different blood taking method which uses the conventional laboratory method to test for coagulation profile of INR. As compared to other hospitals, coagulometer were used in INR monitoring. Thus, patients' data from Hospital Seberang Jaya were excluded to prevent systematic error. The coagulometer used by Hospital Pulau Pinang is CoaguChek Pro II, Hospital Kepala Batas is CoaguChek XS and Hospital Bukit Mertajam is CoaguChek.

\section{STATISTICAL ANALYSIS}

A total of 576 records met the inclusion criteria and were analysed using descriptive statistic to ensure the data (average warfarin dose) collected is normally distributed. To analyse the average warfarin dose between gender the independent sample-t test was used. Factor of race was analysed using analysis of variance (ANOVA), followed by post-hoc test. For correlation of age factor and average warfarin dose, Pearson correlation test was used. All data were expressed as means and standard deviation. If the value of $p<0.05$ then was considered statistically significant.

\section{Key Definitions}

INR stabilisation is the achievement of stable therapeutic INR defined as the first three consecutive INR values in range of 2.0-3.0 after the initiation of warfarin therapy (Nelson et al. 2014). 
INR stabilisation time was defined as the time between the first visit and the third of the three consecutive in-range INR values. INR patterns were expressed using percentage of TTR (Nelson et al. 2014).

TTR was calculated based on Rosendaal et al.'s (1993) method, which uses linear interpolation to assign an INR value to each day between successive observed INR values (Nelson et al. 2014). This approach assumes that INR is linearly increasing or decreasing between measurements and produces a percentage of days when the INR measurements are within a pre-specified range (Nelson et al. 2014).

\section{RESULTS}

A total number of 1,414 patient were followed up under WMTAC warfarin clinic of the four selected hospitals. The number of patient under WMTAC follow up in Hospital Bukit Mertajam, Hospital Kepala Batas, Hospital Pulau Pinang and Hospital Seberang Jaya is 234, 146, 915 and 119, respectively. Eight hundred and thirty-eight patients were excluded from the study and the remaining 576 patients who fulfilled the criteria were selected for this study as shown in Figure 1.

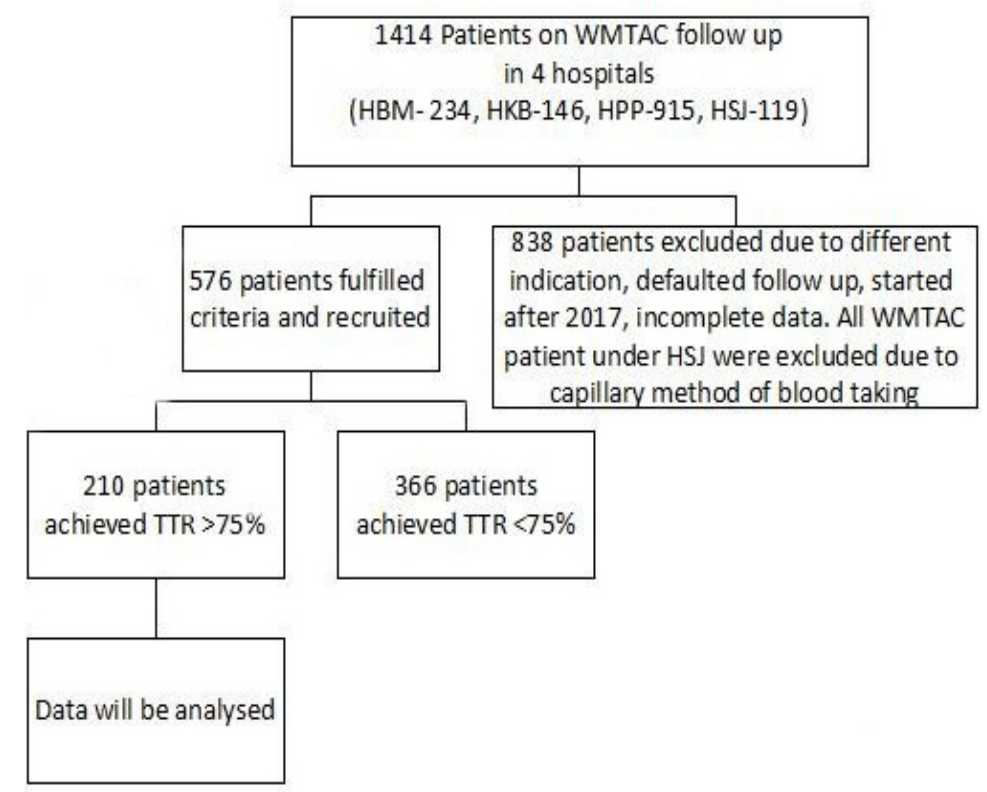

Figure 1: Flowchart of study sample selection of AF patients with TTR $>75 \%$.

Microsoft Excel were formulated according to Rosendaal et al.'s (1993) method shows that only 210 patient has TTR more than $75 \%$. The data is normally distributed and positively skewed. The mean and median of the mean warfarin dose is $3 \mathrm{mg}$ for the whole of study population. Table 1 summarises the patients' characteristics. The mean dose of warfarin for TTR more than $75 \%$ is $3.05 \mathrm{mg} \pm 1.25 \mathrm{mg}$. The average warfarin dose was not significantly different among the gender male and female $(p=0.11)$ according to independent-sample

Malay J Pharm Sci, Vol. 19, No. 2 (2021): 47-60 
$t$-test. The influence of race on the mean warfarin dose appear to be present in between Chinese and Indian races only based on the result of ANOVA test followed by post-hoc test $(p=0.008)$.

Table 1: Average warfarin dose among patients based on gender and race.

\begin{tabular}{llll}
\hline Characteristics & Patients & Average dose $(\mathbf{m g})$ & $\boldsymbol{p}$-value \\
\hline All & $N=210$ & $3.05 \pm 1.25(0.5-7.0)$ & \\
Sex $(n, \%)$ & & & \\
Male & $120(57.1 \%)$ & $3.16 \pm 1.35$ & $0.11 \mathrm{i}$ \\
Female & $90(42.9 \%)$ & $2.90 \pm 1.09$ & \\
Ethnic group $(n, \%)$ & & & \\
Malay & $62(29.5 \%)$ & $3.36 \pm 1.55$ & \\
Chinese & $161(76.7 \%)$ & $* 2.86 \pm 1.10$ & $0.0008 \mathrm{p}$ \\
Indian & $12(5.7 \%)$ & $* 4.11 \pm 1.40$ & \\
Others & $1(0.5 \%)$ & 5.00 & \\
\hline
\end{tabular}

Notes: $\mathrm{i}=$ Independent sample $t$-test, $p=$ post-hoc test; *the result showed statistically significant different of mean warfarin dose among Chinese and Indian population.

Based on Figure 2, there was a pronounced decrease of mean warfarin dose with increasing age of patient. The mean warfarin dose among the age of patient were analysed using Pearson correlation showed weak negative correlation (Pearson value $=-0.125$ ). From Table 2, the frequency of patient achieve TTR more than $75 \%$ was 210 represented only $36.4 \%, 232$ of the patient has less than $60 \%$ of TTR and 134 of them achieved TTR $60 \%-$ $75 \%$ range. The median day to achieve three consecutive targeted INR is 186.5 days for atrial fibrillation patient newly started on warfarin therapy in 2015 until 2016.

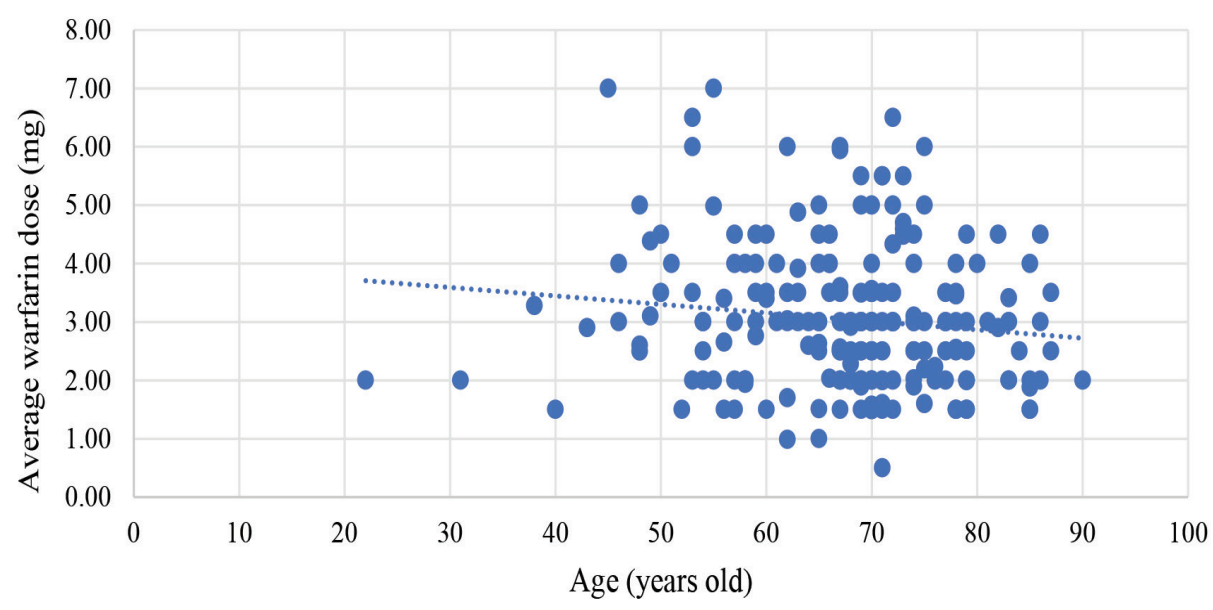

Figure 2: Correlation between age of patient (years old) and average warfarin dose (mg). 
Table 2: Time in therapeutic range of atrial fibrillation patient.

\begin{tabular}{ll}
\hline TTR & Patients $(\boldsymbol{n}, \%)$ \\
\hline All $($ mean $=65.9 \% \pm 22.1 \%)$ & 576 \\
$<60 \%$ & $232(40.3 \%)$ \\
$60 \%-75 \%$ & $134(23.3 \%)$ \\
$>75 \%$ & $210(36.4 \%)$ \\
\hline
\end{tabular}

\section{DISCUSSION}

\section{Ethnicity}

Reports suggested that racial background may influence warfarin dose requirements. According to our findings, Indian patients require the highest dose of warfarin, which was $4.11 \pm 1.40 \mathrm{mg}$. On the other hand, Chinese patients and Malay patients require a much lower average maintenance dose of warfarin compared to the Indian patients, which were $2.86 \pm 1.10 \mathrm{mg}$ and $3.356 \pm 1.55 \mathrm{mg}$, respectively. However, the difference was only significant between the Indians and the Chinese $(p=0.0008)$.

This finding is similar compared with previous study by Gan et al. (2011) who found that Indian patients require a significantly higher average warfarin dose compared to Malay and Chinese patients $(4.9 \pm 1.8 \mathrm{mg}, 3.5 \pm 1.3 \mathrm{mg}$ and $3.3 \pm 1.1 \mathrm{mg}$, respectively). Lal et al. (2008) also reported that the daily warfarin doses were significantly higher in Indians compared to Malays and Chinese $(6.21 \pm 2.94 \mathrm{mg}, 3.28 \pm 1.39 \mathrm{mg}$ and $3.68 \pm$ $1.68 \mathrm{mg})(p<0.001$ in each case). The difference between our findings and the findings of the previous studies could be due to difference in the target INR and indication of warfarin. Gan et al. (2011) included patients with target therapeutic INR of 2.0-3.5, whereas our study included patients with target INR of 2.0-3.0. Lal et al. (2008) on the other hand had a wider exclusion criterion compared to our study, as they excluded patients with congestive heart failure (New York Heart Association [NYHA] class 3 or greater), liver cirrhosis or thyroid disease and patients on medications known to interact with warfarin. Besides, both studies included patients of all indications of warfarin, whereas our study included only patients with atrial fibrillation (Gan et al. 2011; Lal et al. 2008). Difference in average warfarin requirement among various ethnicity can be explained by the genetic variants of vitamin $\mathrm{K}$ epoxide oxidase reductase complex subunit 1 (VKORC1). VKORC1 GG genotype was more commonly seen in Indian patients, whereas AA genotype is more frequent in Malay and Chinese. It was shown that the non-A/non-A genotype require a higher mean daily dose. Polymorphism of the CYP2C9*2 alleles and CYP2C9*3 alleles will also reduce the warfarin enzymatic activity which lead to reduced clearance of warfarin and result in a lower warfarin dose requirement (Gan et al. 2011; Absher, Moore and Parker 2002). Furthermore, genetic mutation in the factor IX propeptide will also cause selective reduction in factor IX during treatment with coumarin drugs and cause the levels of other vitamin K-dependent coagulation factors to decrease to $30 \%$ to $40 \%$ of normal values. These findings are significant in presenting the need to include such requirement in warfarin dose initiation and maintenance, as certain genotypes can be associated with higher risk of adverse events (Ansell et al. 2008).

Malay J Pharm Sci, Vol. 19, No. 2 (2021): 47-60 


\section{Age}

Our present study found that the average warfarin dose requirement decreases with age, with the mean warfarin dose ranging from $2.67 \pm 0.93 \mathrm{mg}$ for age group $>75$ years old -3.38 $\pm 1.40 \mathrm{mg}$ for age group $\leq 45$ years old. However, the association between age and mean warfarin dose was not significant $(p=0.11)$. On the contrary, previous study done by Khoury and Sheikh-Taha (2014) found a significant association between increasing age and the average maintenance dose of warfarin. Khoury and Sheikh-Taha (2014) reported that the mean total weekly dose (TWD) of patients in group 20-29 years old, 30-39 years old and $40-49$ years old was two times higher compared to group 80-89 years old ( $\sim 51 \mathrm{mg}$ versus $24.82 \mathrm{mg} ; p<0.05)$. The difference between our findings and the findings by Khoury and Sheikh-Taha (2014) could be due to the presence of confounding variables in our present study, such as concomitant drugs with major interactions with warfarin, smoking and alcohol consumptions as Khoury and Sheikh-Taha (2014) excluded all such patients. Besides, the indication for warfarin included by Khoury and Sheikh-Taha (2014) was either AF or venous thromboembolism, whereas our study included only AF patients. Liew et al. (2013) on the other hand reported that warfarin dosage requirement correlated negatively with age, decreasing by $1.1 \mathrm{mg}$ per decade within the age range of $45-85$ years old, irrespective of body weight, ethnicity, or sex differences $(p<0.001)$. Garcia et al. $(2005)$ also reported that the TWD declines by $0.4 \mathrm{mg}$ per year of life.

It was suggested that the decreased serum proteins, metabolic activities and excretion through the kidneys of elderly patients contributed to the increased sensitivity to warfarin (Shepherd et al. 1977).

However, Shepherd et al. (1977) revealed that there was no appreciable difference in the pharmacokinetics of warfarin, i.e. the plasma half-life, apparent volume of distribution, plasma clearance and plasma warfarin metabolite levels, between younger and older patients. This suggests that increase in age-dependent warfarin sensitivity did not influenced by pharmacokinetic factors. Elderly patients are more likely to take multiple medications which may increase the risk of drug-drug interactions that possibly potentiate warfarin effects (Garcia et al. 2005). Inhibition of synthesis of vitamin K dependent clotting factors are much greater in elderly compared to young patients at similar warfarin plasma concentrations (Mangoni and Jackson 2004). Furthermore, the differences in intake of vitamin $\mathrm{K}$ containing food will also affect the average dose of warfarin in patients.

\section{Gender}

According to our findings, male patients require an approximately $0.26 \mathrm{mg}$ higher mean daily warfarin dose than women but was not statistically significant $(p=0.06)$. This finding is similar compared with previous studies by Whitley et al. (2007) who reported that female patients require $0.36 \mathrm{mg}$ lower total daily warfarin dose than males. Khoury and SheikhTaha (2014) reported that women required a $0.46 \mathrm{mg}$ lower total daily dose of warfarin than men. Both studies showed that the differences were insignificant.

Conversely, several published articles cite gender to be an important factor in predicting warfarin dose (Garcia et al. 2005; Liew et al. 2013; Ansell et al. 2004; Absher, Moore and Parker 2002; Oates et al. 1998). Ansell et al. (2004) showed that women require an average of $0.64 \mathrm{mg}$ lower of warfarin dose per day. Regardless of the effect gender plays in warfarin dosing, studies are consistent in reporting lower doses required for women compared with men. 
The sensitivity difference in each gender could be contributed by the biological difference between men and women. Generally, men are bigger in size than women, which leads to a larger distribution volumes and faster warfarin clearance. In addition, glomerular filtration, renal tubular secretion and reabsorption are faster in men. This may result in faster clearance of warfarin in men compared to women as warfarin is mainly eliminated renally ( 92\%) (Schwartz 2003).

\section{Average TTR of Penang Population}

TTR is the optimal measure of INR control and has a significant relationship with adverse outcomes in all studies. This is shown by Jones et al. (2005) who reported that a $10 \%$ increase in time out of therapeutic range in AF patient was associated with an increased risk of ischemic stroke (odds ratio $=1.10 ; p=0.006$ ). Wan et al. $(2008)$ also reported that a $6.9 \%$ increase in TTR significantly reduced major haemorrhage by 1 event per 100 patient-years (95\% Cl: 0.29 to 1.71 events) and an $11.9 \%$ increase in TTR reduced thromboembolic events by 1 event per 100 patient-years (95\% Cl: 0.01 to 2.02 events). A similar study by Connolly et al. (2008) also showed a 5\% improvement in TTR across UK anticoagulation clinics would prevent 400-500 strokes per year. These studies signify the importance of a high TTR value as it represents the quality of anticoagulation treatment.

In the present study, we found that the average TTR of the Pulau Pinang population was $65.9 \% \pm 22.1 \%$ which is comparable with previously reported studies. Edwards et al. (2014) and Thanimalai et al. (2013) reported the average TTR of $66 \%$ and $65.1 \%$ in patients in Sarawak, Malaysia and Hospital Kuala Lumpur, respectively. Whereas Yap et al. (2017) and Ainina, Farhana and Nur'ain (2015) reported a slightly lower average TTR of $52 \% \pm 18.7 \%$ in National Heart Institute, Kuala Lumpur and $60.6 \% \pm 19.1 \%$ in in Hospital Kemaman, Terengganu, respectively.

A marked benefit was found against stroke and total vascular events for patients on oral anticoagulant treated at centres that had mean TTRs above the study median of $65 \%$; no apparent benefit was found for the other half of patients with mean TTRs below $65 \%$ (Connolly et al. 2008). It was shown that average TTR $>65 \%$ reduced vascular events by $>2$-fold (relative risk, $2.14 ; 95 \% \mathrm{Cl}: 1.61$ to $2.85 ; p<0.0001$ ) compared to TTR $<65 \%$ whereas TTR $<58 \%$ would not generate a net clinical benefit (Connolly et al. 2008). Veeger et al. (2005) reported increased rates of recurrent venous thromboembolism and major bleeding when patients with TTR $<45 \%$ were compared with those having TTR $>65 \%$.

White et al. (2007) categorised patients into poor control group, $(<60 \%)$ moderate control group (TTR 60\%-75\%) and good control group (TTR > 75\%) and demonstrated that poor control group have a higher risk of myocardial infarction, stroke and systemic embolism event. Our results showed that 232 out of 576 patients $(40.3 \%)$ have poor INR control (TTR < 60\%), 134 out of 576 patients $(23.3 \%)$ have moderate INR control (TTR $60 \%-75 \%)$ and 210 out of 576 patients (36.4\%) have good INR control (TTR > 75\%) (White et al. 2007). The study by White et al. (2007) showed that the annual mortality (4.20\%) and major bleeding $(3.85 \%)$ of the poor control group is higher compared with the moderate control group (TTR $60 \%-75 \%)(1.84 \%$ and $1.96 \%)$.

There are several factors associated with poor anticoagulation control which lead to a low TTR value. Several studies reported patients who are females, advanced age (> 75 years old) and heart failure are associated with poor INR control (Melamed et al. 2011; Costa et al. 2012; Zubaid et al. 2013). This may be associated with the significantly higher thrombin levels in females compared to males as reported by Lim et al. (2014). Lim et al. (2014) reported that plasma thrombin levels correlated well with TTR status, with higher levels found in patients with suboptimal INR control. Thrombin levels may be a

Malay J Pharm Sci, Vol. 19, No. 2 (2021): 47-60 
useful marker in reflecting the quality of anticoagulation and in identifying poorly controlled warfarin patients. Adherence to medication is one of the factors of a significant decrease in good control rates observed by Farsad et al. (2016) when the patients were prescribed more than four medications. It suggested that the number of prescribed medications may be an important factor in influencing patient adherence to warfarin therapy that can affect TTR indirectly. This is supported by Zullig et al. (2015), who reported that having too many medications to take is a barrier to medication adherence.

\section{INR STABILISATION TIME}

Difficulties in achieving therapeutic INR for newly initiated warfarin patients are commonly focused by most of the studies, only fewer studies focus on achievement of INR stabilisation time (Nelson et al. 2014). In this study, we aimed to find the INR stabilisation time and found that the median day to achieve three consecutive targeted INR is 186.5 days for $111 \mathrm{AF}$ patients (97.4\%) who are newly started on warfarin therapy in 2015 until 2016.

In the study conducted by Nelson et al. (2014), data of 15,276 non-valvular atrial fibrillation (NVAF) patients with $\geq 3$ INR values were analysed from a large United States electronic database collected from 2006 to 2010 and were followed from warfarin initiation to the first $\geq 90$-day gap or end of the data time frame. Nelson et al. (2014) found that the mean days to INR stabilisation for INR stabilisation achievers $(75.1 \%)$ was $129.1 \pm 2.4$ days. As for Rombouts, Rosendaal and van der Meer $(2009)$, $(N=13,443)$ which studies on the risk factors of subtherapeutic INR patients, the INR stability was defined as four consecutive in range INR measurements and further defined as 2.0-3.5 for low-intensity treatment and 2.5-4.0 for high-intensity treatment. Rombouts, Rosendaal and van der Meer (2009) found that $55 \%$ patients achieved INR stabilisation with the average time to stabilisation of 12 weeks. Witt et al. (2009) analysed data of 6,073 patients receiving warfarin retrospectively to identify the determinants of stable INR and has defined INR stabilisation as having all INR within the therapeutic range for any continuous 6 -month period and found that $41 \%$ of their patients achieved INR stabilisation. The difference probably is due to the fact that the definition of time to INR stabilisation, number of consecutive in range INR measurements, duration of patient monitoring and inclusion of various warfarin indications were differed in each study as there are no standard to determine the appropriate criteria of INR stabilisation. Besides, the number of INR measurements or follow ups and the large sample size difference could be the factors of the difference of the INR stabilisation time.

\section{CONCLUSION}

In conclusion, this study found that the average warfarin dose in AF patient to achieve therapeutic INR range of $2-3$ with TTR $>75 \%$ is $3.05 \pm 1.25 \mathrm{mg}$. Indian patients required a statistically significantly higher warfarin dose than Chinese patients. Mean warfarin doses were not affected by age and sex. The average TTR among 576 patients in our study is $65.9 \% \pm 22.1 \%$. The median day to achieve three consecutive targeted INR is 186.5 days for $111 \mathrm{AF}$ patients (97.4\%) who were newly started on warfarin therapy in 2015 until 2016. 


\section{LIMITATIONS}

There are few limitations of this study. This study is a retrospective and relies upon extraction of data from administrative databases and medical records. Factors such as Vitamin $\mathrm{K}$ intake, comorbidities and concomitant drugs used could be affecting warfarin dose in clinical decision were not collected in view that the data may not be updated. Our study has a relatively small sample size and may not be adequately powered to detect a statistically significant difference. This is because the small sample size under-represents various ethnic groups, as well as age group, thus possibly prevents us from drawing conclusions regarding warfarin requirements in these individuals. Rosendaal et al.'s (1993) method may also be biased by individual INR values that are far outside of TTR as Rosendaal et al.'s (1993) method assumes that the change in INR over time is linear between each timepoint, which may not be true. This may lead to an over-estimation or an under-estimation of TTR value for patients. This research is a multicentre study and involves three different hospitals. The different types of coagulometer used by the hospitals may lead to variability in the INR reading due to the respective standard errors.

\section{RECOMMENDATIONS}

These observations suggest that the current initiation and maintenance doses of warfarin may be reviewed and tailored to patients to reduce the risk of inadequate therapy in Indian patients and excessive anticoagulation in the Chinese patients. Further studies with a greater samples size in this area may more precisely predict the average warfarin dose among these different patient-specific factors. More effort should also be taken to improve the TTR of patients in the poor and moderate control group. The recent American College of Chest Physician guidelines have suggested the practice of three techniques to improve TTR namely establishing anticoagulation clinics, application of computerised dose adjustment systems and patient self-monitoring. However, the use of computerised dose adjustment systems and patient self-monitoring warrant further evaluation before its implementation in a primary care setting.

\section{ACKNOWLEDGEMENTS}

We would like to thank the Director General of Health, Ministry of Health Malaysia for his continuous support for this study and permission to publish this report.

\section{REFERENCES}

ABSHER, R. K., MOORE, M. E. \& PARKER, M. H. (2002) Patient-specific factors predictive of warfarin dosage requirements, The Annals of Pharmacotherapy, 36(10): 1512-1517. https://doi.org/10.1345/aph.1C025

AININA, N. B. S., FARHANA, N. Y. S. \& NUR'AIN, S. M. S. (2015) Effects of pharmacist managing warfarin medication therapy adherence clinic in Kemaman Hospital, Medical Journal of Malaysia, 70(Suppl 1). http://www.e-mjm.org/2015/v70s1/mjm-sept-suppl-2215. html

Malay J Pharm Sci, Vol. 19, No. 2 (2021): 47-60 
ANSELL, J., HIRSH, J., HYLEK, E., JACOBSON, A., CROWTHER, M. \& PALARETI, G. (2008) Pharmacology and management of the vitamin K antagonists: American College of Chest Physicians Evidence-Based Clinical Practice Guidelines. $8^{\text {th }}$ edition, Chest J, 133(6 Suppl): 160S-198S. https://doi.org/10.1378/chest.08-0670

ANSELL, J., HIRSH, J., POLLER, L., BUSSEY, H., JACOBSON, A. \& HYLEK, E. (2004) The pharmacology and management of the vitamin $\mathrm{K}$ antagonists: The seventh ACCP Conference on Antithrombotic and Thrombolytic Therapy, Chest, 126(3 Suppl): 204S-233S. https://doi.org/10.1378/chest.126.3_suppl.204S

BRASS, L. M., KRUMHOLZ, H. M., SCINTO, J. M. \& RADFORD, M. (1997) Warfarin use among patients with atrial fibrillation, Stroke, 28(12): 2382-2389.

CONNOLLY, S. J., POGUE, J., EIKELBOOM, J., FLAKER, G., COMMERFORD, P., FRANZOSI, M. G. et al. (2008) Benefit of oral anticoagulant over antiplatelet therapy in atrial fibrillation depends on the quality of international normalized ratio control achieved by centers and countries as measured by time in therapeutic range, Circulation, 118(20): 2029-2037. https://doi.org/10.1161/CIRCULATIONAHA.107.750000

COSTA, G. L., LAMEGO, R. M., COLOSIMO, E. A., VALACIO, R. A. \& MOREIRA, M. (2012) Identifying potential predictors of high-quality oral anticoagulation assessed by time in therapeutic international normalized ratio range: A prospective, long-term, single-center, observational study, Clinical Therapeutics, 34(7): 1511-1520. https://doi.org/10.1016/j. clinthera.2012.06.002

DANG, M.-T. N., HAMBLETON, J. \& KAYSER, S. R. (2005) The influence of ethnicity on warfarin dosage requirement, Annals of Pharmacotherapy, 39(6): 1008-1012. https://doi. org/10.1345/aph.1E566

EDWARDS, F., ARKELL, P., FONG, A. Y. Y., ROBERTS, L. M., GENDY, D., WONG, C. S. H. et al. (2014) Bleeding events and associated factors in a cohort of adult patients taking warfarin in Sarawak, Malaysia, Journal of Thrombosis and Thrombolysis, 38(2): 226-234. https://doi.org/10.1007/s11239-013-1017-6

FARSAD, B. F., ABBASINAZARI, M., DABAGH, A. \& BAKSHANDEH, H. (2016) Evaluation of time in therapeutic range (TTR) in patients with non-valvular atrial fibrillation receiving treatment with warfarin in Tehran, Iran: A cross-sectional study, Journal of Clinical and Diagnostic Research, 10(9): FC04-FC06. https://doi.org/10.7860/JCDR/2016/21955.8457

GAN, G. G., PHIPPS, M. E., LEE, M. M., LU, L. S., SUBRAMANIAM, R. Y., BEE, P. C. et al. (2011) Contribution of VKORC1 and CYP2C9 polymorphisms in the interethnic variability of warfarin dose in Malaysian populations, Annals of Hematology, 90(6): 635641. https://doi.org/10.1007/s00277-010-1119-6

GARCIA, D., REgAN, S., CROWTHER, M., HUGHES, R. A. \& HYLEK, E. M. (2005) Warfarin maintenance dosing patterns in clinical practice: Implications for safer anticoagulation in the elderly population, Chest, 127(6): 2049-2056. https://doi.org/10.1378/ chest.127.6.2049 
JONES, M., MCEWAN, P., MORGAN, C. L., PETERS, J. R., GOOdFELlOW, J. \& CURRIE, C. J. (2005) Evaluation of the pattern of treatment, level of anticoagulation control, and outcome of treatment with warfarin in patients with non-valvar atrial fibrillation: A record linkage study in a large British population, Heart (British Cardiac Society), 91(4): 472-477. https://doi.org/10.1136/hrt.2004.042465

KHOURY, G. \& SHEIKH-TAHA, M. (2014) Effect of age and sex on warfarin dosing, Clinical Pharmacology: Advances and Applications, 6: 103-106. https://doi.org/10.2147/ CPAA.S66776

LAL, S., SANDANARAJ, E., JADA, S. R., KONG, M. C., LEE, L. H., GOH, B. C., et al. (2008) Influence of APOE genotypes and VKORC1 haplotypes on warfarin dose requirements in Asian patients. British Journal of Clinical Pharmacology, 65(2): 260-264. https://doi.org/10.1111/j.1365-2125.2007.03053.x

LIEW, C. L., YEN, J. H., LIU, A. B. \& LIU, I. Y. (2013) Sex differences in the effective warfarin dosage in Han and aboriginal Taiwanese patients with the VKORC1-1639AA genotype, Tzu Chi Medical Journal, 25(4): 213-217.

LIM, M., ANCHAH, L., TIONG, W., HWANG, S., ONG, T., SIM, K. et al. (2014) Thrombin and $\mathrm{FXa}$ plasma concentration levels in patients with atrial fibrillation on long term warfarin therapy, ASEAN Heart Journal, 22: 1-10.

MANGONI, A. A. \& JACKSON, S. H. (2004) Age-related changes in pharmacokinetics and pharmacodynamics: Basic principles and practical applications, British Journal of Clinical Pharmacology, 57(1): 6-14. https://doi.org/10.1046/j.1365-2125.2003.02007.x

MELAMED, O. C., HOROWITZ, G., ELHAYANY, A. \& VINKER, S. (2011) Quality of anticoagulation control among patients with atrial fibrillation, The American Journal of Managed Care, 17(3): 232-237.

NELSON, W. W., DESAI, S., DAMARAJU, C. V., LU, L., FIELDS, L. E., WILDGOOSE, P. et al. (2014) International normalized ratio stabilization in newly initiated warfarin patients with nonvalvular atrial fibrillation, Current Medical Research and Opinion, 30(12): 24372442. https://doi.org/10.1185/03007995.2014.957822

OATES, A., JACKSON, P. R., AUSTIN, C. A. \& CHANNER, K. S. (1998) A new regimen for starting warfarin therapy in out-patients. British Journal of Clinical Pharmacology, 46(2): 157-161. https://doi.org/10.1046/j.1365-2125.1998.00755.x

OHARA, M., TAKAHASHI, H., LEE, M. T. M., WEN, M-S., LEE, T-H., CHUANG, H-P. et al. (2014) Determinants of the over-anticoagulation response during warfarin initiation therapy in Asian patients based on population pharmacokinetic-pharmacodynamic analyses, PLOS One, 9(8): e105891. https://doi.org/10.1371/journal.pone.0105891

POKORNEY, S. D., SIMON, D. N., THOMAS, L., FONAROW, G. C., KOWEY, P. R., CHANG, P. et al. (2015) Patients' time in therapeutic range on warfarin among US patients with atrial fibrillation: Results from ORBIT-AF registry, American Heart Journal, 170(1): 141. e1-148.e1. https://doi.org/10.1016/j.ahj.2015.03.017

Malay J Pharm Sci, Vol. 19, No. 2 (2021): 47-60 
ROMBOUTS, E. K., ROSENDAAL, F. R. \& VAN DER MEER, F. J. (2009) Subtherapeutic oral anticoagulant therapy: Frequency and risk factors, Thrombosis and Haemostasis, 101(3): 552-556.

ROSENDAAL, F. R., CANNEGIETER, S. C., VAN DER MEER, F. J. \& BRIËT, E. (1993) A method to determine the optimal intensity of oral anticoagulant therapy, Thrombosis and Haemostasis, 69(3): 236-239.

SCHWARTZ J. B. (2003) The influence of sex on pharmacokinetics, Clinical Pharmacokinetics, 42(2): 107-121. https://doi.org/10.2165/00003088-200342020-00001

SHEPHERD, A. M., HEWICK, D. S., MORELAND, T. A. \& STEVENSON, I. H. (1977) Age as a determinant of sensitivity to warfarin, British Journal of Clinical Pharmacology, 4(3): 315-320. https://doi.org/10.1111/j.1365-2125.1977.tb00719.x

SONUGA, B. O., HellenBerg, D. A., CuPIDO C. S. \& JAEGER, C. (2016) Profile and anticoagulation outcomes of patients on warfarin therapy in an urban hospital in Cape Town, South Africa, African Journal of Primary Health Care \& Family Medicine, 8(1): 1032.

THANIMALAI, S., SHAFIE, A. A., HASSALI, M. A. \& SINNADURAI, J. (2013) Comparing effectiveness of two anticoagulation management models in a Malaysian tertiary hospital, International Journal of Clinical Pharmacy, 35(5): 736-743. https://doi.org/10.1007/ s11096-013-9796-6

VEeger, N. J., PIERSMA-WICHERS, M., TIJSSEN, J. G., HILLEGE, H. L. \& VAN DER MEER, J. (2005) Individual time within target range in patients treated with vitamin $\mathrm{K}$ antagonists: Main determinant of quality of anticoagulation and predictor of clinical outcome. A retrospective study of 2300 consecutive patients with venous thromboembolism, British JournalofHaematology, 128(4): 513-519. https://doi.org/10.1111/j.1365-2141.2004.05348.x

WAN, Y., HENEGHAN, C., PERERA, R., ROBERTS, N., HOLLOWELL, J., GLASZIOU, P. et al. (2008) Anticoagulation control and prediction of adverse events in patients with atrial fibrillation: A systematic review, Circulation. Cardiovascular Quality and Outcomes, 1(2): 84-91. https://doi.org/10.1161/CIRCOUTCOMES.108.796185

WHITE, H. D., GRUBER, M., FEYZI, J., KAATZ, S., TSE, H. F., HUSTED, S. et al. (2007) Comparison of outcomes among patients randomized to warfarin therapy according to anticoagulant control: Results from SPORTIF III and V, Archives of Internal Medicine, 167(3): 239-245. https://doi.org/10.1001/archinte.167.3.239

WHITLEY, H. P., FERMO, J. D., CHUMNEY, E. C. \& BRZEZINSKI, W. A. (2007) Effect of patient-specific factors on weekly warfarin dose, Therapeutics and Clinical Risk Management, 3(3): 499-504.

WITT, D. M., DELATE, T., CLARK, N. P., MARTELL, C., TRAN, T., CROWTHER, M. A. et al. \& WARFARIN ASSOCIATED RESEARCH PROJECTS AND OTHER ENDEAVORS (WARPED) CONSORTIUM (2009) Outcomes and predictors of very stable INR control during chronic anticoagulation therapy, Blood, 114(5): 952-956. https://doi. org/10.1182/blood-2009-02-207928 
YAP, S. H., NG, Y. P., ROSLAN, A., KOLANTHAIVELU, J., KOH, K. W., P'NG, H. S. et al. (2017) A comparison of dabigatran and warfarin for stroke prevention in elderly Asian population with non-valvular atrial fibrillation: An audit of current practice in Malaysia, The Medical Journal of Malaysia, 72(6): 360-364.

ZUBAID, M., SAAD, H., RIDHA, M., MOHANAN NAIR, K. K., RASHED, W., ALHAMDAN, R. et al. (2013) Quality of anticoagulation with warfarin across Kuwait, Hellenic Journal of Cardiology, 54(2): 102-106.

ZULLIG, L. L., STECHUCHAK, K. M., GOLDSTEIN, K. M., OLSEN, M. K., MCCANT, F. M., DANUS, S. et al. (2015) Patient-reported medication adherence barriers among patients with cardiovascular risk factors, Journal of Managed Care and Specialty Pharmacy, 21(6): 479-485. https://doi.org/10.18553/jmcp.2015.21.6.479

Malay J Pharm Sci, Vol. 19, No. 2 (2021): 47-60 